\title{
The effect of intensities of comparative ease and interaction on comparative knowledge gained from online and face-to-face learning modes
}

\section{Bikash Shrestha ${ }^{1}$ and Arhan Sthapit, $\mathrm{PhD}^{2}$}

${ }^{1}$ Lecturer, Faculty of Management,

Tribhuvan University, Nepal, https://orcid.org/0000-0002-1081-461X, bikashshrestha@kcm.edu.np

${ }^{2}$ Professor, Faculty of Management \& Law, Nepal Open University, Nepal, https://orcid.org/0000-0002-2799-4936, arhan@nou.edu.np

Received on: Nov 12, 2021

Revised on : Dec 11, 2021

Accepted on: Dec 20,2021

\section{Cite this paper}

Shrestha, B. and Sthapit, A. (2021). The effect of intensities of comparative ease and interaction on comparative knowledge gained from online and faceto-face learning modes. International Research Journal of Management Science, vol.6(1), pp. 1-16

\begin{abstract}
The paper examined the effect of varying intensities of comparative interaction level (CIL_L) and comparative ease of attending online classes (CE_L) (viz., high, and low) on comparative knowledge gained from online and face-to-face learning modes, and existence of differences on the effect across two intensities of the covariates. Based on complete enumeration of the population of 224 management students attending the online classes at Nepal Open University, Nepal (from 22nd February to 29th March 2020), the study - by employing a binary logistic regression modeldiscovered the effect of comparative interaction level and comparative ease of attending online classes as significant on the comparative gain of knowledge. Further, the study found that the effect of low intensities of comparative ease of attending online classes (CE_L) and comparative interaction level (CIL_L) are lower than high intensities of comparative interaction level and comparative ease of attending online classes in finding the online classessimilar/superior as opposed to the face-to-face classes. The findings should be instrumental to the exploration of the potential pathways to ameliorate the virtual learning mode as an alternative to the face-to-face one in Nepalese higher education regime.
\end{abstract}

Keywords: comparative knowledge gained, comparative ease, comparative interaction, face-to-face learning, online learning 


\section{Introduction}

A teaching and technology theory is a philosophical paradigm that embodies those principles from which we view different aspects of education, including e-learning (Zinn, 1990). E-learning technologies, according to Dahlberg (2004), can effectively respond to accelerating global competition, boost learning experiences (Garrison, Anderson, \& Archer, 2001), and have serious, fast, and disruptive effects on education systems (Archer, Garrison, \& Anderson, 1999). Efficient new software offers quick access to human capital, materials, and knowledge as learning opportunities expand. Less complex technology, when used correctly, can promote exploration, and help students explore new information (Valdez, et al., 2000). The hard and soft technology systems that allow and sustain online learning are extremely complex and technically advanced (Kearsley, 2000). All of this has an impact on the ease of learning as well as the promotion of interactions between teachers and students in e-learning platforms.

The Web and the Internet have turned out tremendous enhancements to essentially all parts of our lives, ranging from an overall economy, individual, and expert organisations to various wellsprings of information, and learning (Pape, 2010). Farinella, Hobbs, and Weeks (2000) declared that the internet has made online learning possible, and various experts and educators are enthusiastic about the web sorting out some way to overhaul and further develop students' learning results while combating the decline in resources, especially in high level education. Various terminologies have been used for internet learning, which makes it hard to build up a conventional definition. Terms commonly used for online learning are e-learning, web learning, tele-learning, virtual learning, electronic learning, and distance learning (Anderson, 2008). These terms recommend that the students are far away from the mentor or educator, that the student utilizes a type of progression (generally a PC) to get to the learning materials, that the students use improvement to interface with the educators and with different stakeholders.

Carliner (1999) characterised web-based learning as instructive material that is introduced on a PC. Essentially, Khan (1997) characterized online guidance as a creative methodology for delivering guidance to a far-off student, utilizing the internet as the medium. Bartley and Golek (2001) viewed web-based learning as a type of distance learning, which has for quite some time been a part of the American learning framework, and it has now turned into the biggest area of learning as of late everywhere. However, Ritchie and Hoffman (1997) confirmed neither putting data online nor connecting to other computerized resources online comprises online learning. Online learning happens when students use the internet to encounter the progression of direction, to finish the learning works out, and to achieve learning results and purposes. Web based learning, in any case, includes something beyond the introduction and conveyance of materials utilising the Web: the student and the learning procedure ought to be the focal point of web-based learning.

Allen and Seaman (2011)identified that online learning has become such an integral part of higher education that 65 per cent of the higher education institutions include online learning as a critical part of their long-term strategy. Even in a Gallup poll conducted on 1,967 faculty members before the COVID-19 pandemic, Lederman (2019) found the 'slow and steady' acceptance of online learning by the university teachers. Likewise, the online mode of learning has emerged as a popular and viable alternative to the traditional learning system across the world in recent times. In Nepal where there are 11 universities and two national health/ medical institutes (Sthapit, 2020), the online learning system and full-fledged online academic degrees were formally and institutionally launched with the establishment of Nepal Open 
University (NOU) in 2016 under the Nepal Open University Act, 2016 (2073 Bikram Era). The NOU launched online classes from fiscal year 2017/18 (NOU, 2020). Tribhuvan University also established the Open and Distance Education Centre in 2015 (ODEC, 2020), yet its classes are largely based on distance education rather than on the exclusive online mode (Sthapit, \& Shrestha, 2020).

With the outbreak of novel coronavirus pandemic from the turn of the early 2020, conventional face-toface classes have been brought to a complete halt, making the internet-based classes as most likely the main elective method of learning. Thus, a greater part of instructive establishments all throughout the world selected running the internetbased classes. The emanant learning climate has notwithstanding, raised the issue if students have seen any distinction between the degrees of information acquired from these two modes. In this unique circumstance, a concentrate by Platt, Ralie, and Yu (2014) stated that near information acquired was one of the critical measurements to the apparent comparability of on the web and vis-à-vis conventional classes.

To the extent that the relative degree of communication and similar straightforwardness in the two methods of learning (specifically, on the web and vis-à-vis conventional modes) are concerned, high and low levels can be the two vital sorts of force. The present study is interested in examining the effect of these two types of intensity (high and low intensities) of comparative interaction level and comparative ease (of attending technology-supported online classes) on the knowledge gained from online and facetoface modes. Sthapit and Shrestha (2020) examined the perceived difference between knowledge gained from the online and that from the face-to-face learning mode in Nepal by applying descriptive statistics and a factorial ANOVA using the General Linear Model.

Gautam and Gautam (2021) identified infrastructure, students, and faculty members, as the three antecedents of effectiveness of online classes during the COVID pandemic, while the study found technological support, infrastructure availability, faculty and students' perception being significantly associated with the effectiveness of the online mode of the teaching-learning process. It also discovered that the students' higher level of willingness to learn would reduce their level of anxiety, which they faced during the coronavirus pandemic.

Besides this, the issue of comparative knowledge gained from these online and face-toface modes of learning and the effect of intensities of class-taking ease on comparative gain of knowledge has remained either non-existent or extremely under-researched; let alone the study of the same in Nepalese context.

\section{Study objectives}

The present study aimed at investigating and predicting the category of similarity or dissimilarity of knowledge gained in terms of the effect of intensities of comparative ease of attending online classes and level of interaction on knowledge gained from online and face-to-face learning modes in management courses in Nepal. The main aim is achieved through the following specific objectives:

- To explore the existence of differences in comparative knowledge gained across intensities of comparative ease of attending online classes and level of interaction among the NOU management students, and 
- To examine the effect of intensities of comparative ease of attending online classes and level of interaction on the knowledge gained from online and face-to-face modes of learning

\section{Literature review}

This section discusses the review of literature concerning the perceived difference between knowledge gained from online and face-to-face learning because of the intensities (viz., high and low) of comparative interaction level and comparative ease of attending the classes.

Dewey (1938) defined learning as a remarkably complex process influenced by a wide variety of factors. There are a number of theories proposed over the years to help explain how people learn. Bandura (1977) postulated social learning theory, which explains human behaviour in terms of continuous reciprocal interaction between cognitive, behavioural, and environmental influences. The emphasis on creating engaged learners who replicate what they have learned has made social learning theory attractive to educators (Nguyen, 2015). One of the big takeaways from social learning theory is the importance of maintaining engaged students and modelling behaviour for those students through a series of interactions such as teacher-students, students-student, and students-teacher during studies.

\subsection{Review of empirical studies}

Seventy-two percent of companies believe that online learning puts them at a competitive edge (Bhat, 2020). Further, a study by IBM reported that those enrolled in eLearning courses learn five times more compared to traditional courses. Today, many companies, universities, industry leaders, employees, and students recognise the benefits of eLearning. Online courses are a convenient, cheaper, and engaging way to learn compared to traditional courses.

However, some studies found no significant differences between online and face-to-face classes in terms of knowledge gained (Clark \& Jones, 2001; Hollerbach \& Mims, 2007; Johnson, Aragon, Shaik, \& PalmaRivas, 2000; Horspool \& Yang, 2010; Sthapit \& Shrestha, 2020). Many other empirical studies, however, show variations in comparative knowledge gained from the two modes of learning. In an Italian study carried out by Schettini, Amendola, Borsini, and Galassia (2020) on a university's chemistry students, the online mode was found to result in increased knowledge acquisition evidenced by an 11 per cent rise in the students passing the exams. The study reported a positive correlation between the time spent on the online platform and the scores secured by students in the exams. On the similar line, Koory (2003) earlier found that students gained greater knowledge from online classes while the studies of Cryan, Mentzer, and Teclehaimanot (2007) reported superior results from face-to-face classes. The study findings of Platt et al., (2014) posited that the amount of experience with online classes influences student perceptions of knowledge gained. Sthapit and Shrestha (2020) discovered the similar findings, i.e., the perception of knowledge gained is superior for the students perceiving ease of attending the online class. Students with less exposure to online courses perceived the online learning mode as less contributing than the facetoface one. Nonetheless, Platt et al. (2014) has left it open for future researchers to probe into what else affects the learner perceptions of comparative knowledge gained from the two modes. Hence, a part of this lacuna is being addressed by the present study.

Interaction has long been a defining and critical component of the educational process and context 
(Anderson, 2003). However, the term used in many ways to describe many different types of exchanges between different actors and objects associated with teaching and learning (Berge, 1999). It is surprisingly hard to locate a reasonable and exact meaning of this multifaceted idea in the education writing. The compositions of Dewey (1938) alluded to association as the characterising part of the educational procedure that happens when students change the latent data passed to them from another and construct it into knowledge with personal application and value (Dron, 2007).

Shank (1993) ) viewed the value of another person's perspective, usually gained through interaction, is a key learning component in constructivist learning theories and in inducing mindfulness in learners (Visser, 2000). Similarly, Laurillard (1997) constructed a conversational model of learning in which interaction between students and teachers plays the critical role. A Moroccan study by Bourzgui, Alami, and Diouny (2020) conducted in the area of dental education emphasised on the need for promoting interactions in learning and evaluation (tests) on e-learning platforms in order to improve the knowledge delivery and help students achieve their desired outcomes. Sthapit and Shrestha (2020) confirmed that the superior knowledge gain resulted from the higher level of interaction in the class than that from a lower level of interaction. Hence, there is a long history of study and acknowledgment of the basic role of association in supporting and in any event, characterising education. In this regard, the study attempts to see the effect of level of comparative level of interaction on comparative knowledge gained.

In this regard, the present study has attempted to assess the effect of varying levels of intensities of comparative ease of attending online classes (using technology) and comparative level of interaction on the comparative knowledge gained from the online and face-to-face learning.

\subsection{Study framework}

In light of the literature survey, the degree of comparative interaction and comparative ease of attending online classes can bring about two intensities: high and low. That the forces of apparent comparative interaction and comparative ease of attending online classes being 'high' and 'low' can affect the comparative knowledge gained from online and face-to-face learning is something yet to be set up. There is a marked research gap, as no past exploration work managing these issues was found during the current investigation. Therefore, the burning issues discussed in the area constitute the main research topic of the present study as exhibited in the conceptual framework (Fig 1).

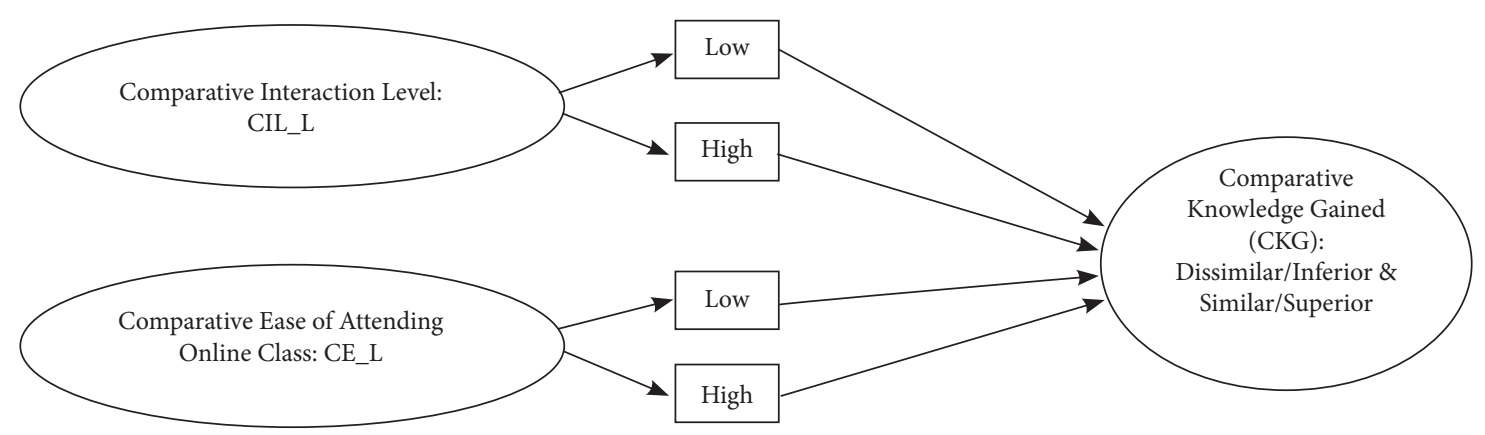

Figure 1. Conceptual framework of the study 


\section{Research methodology}

This section presents the methodological approach to research, nature of data, data collection instrument and analytical tools.

\subsection{Design and data}

The study adopted descriptive and causal research designs. In view of the nature and scope of the study, the primary data was collected from business course students at Nepal Open University (NOU), the only Nepalese university offering full-fledged online learning system in bachelor and masters' programmes for the last two years in Nepal. The survey covered all the business/ management programmes being offered by the Faculty of Management and Law at the Bachelors' and Masters' levels. The study has, therefore, encompassed the students who have enrolled and undergone online classes at least six months prior to the survey. The need for sampling is irrelevant as the study used a complete enumeration of all business students of NOU.

The survey under the complete enumeration scheme (entire population) was administered with the prior approval from the programme coordinators of the management programmes of the university from $22 \mathrm{nd}$ February to 29th March 2020 - on all 228 management students, of which 224 responses were retained as four were found either incomplete or incompatible. The total pool of respondents is constituted by 140 students from the masters' level (62.5 per cent) and 84 from the bachelor levels (37.5 per cent) as presented in Appendix 2. It is a study conducted prior to the COVID-19 pandemic that has forced the physical classes to be either closed or suspended indefinitely. Hence, it does not encompass the virtual learning issues specific of the pandemic.

The questionnaire included a set of close-ended questions on comparative knowledge gained, comparative level of interaction and comparative ease previously tested in the study of Platt, et al. (2014), and Sthapit and Shrestha (2020), by recasting and modifying some of the items in accordance with the research objectives of the present study. Conspicuously, the questionnaire required the respondents to compare their present experience of online learning with their previous experience with the face-to-face learning, which they have had during their previous academic degree. It is obvious that the respondents are in a position to make comparisons between the two modes of learning, as they were engaged in traditional, face-to-face learning mode till the point they have joined their current alma mater Nepal Open University that has in recent times exposed them to the online mode.

All items used a Likert-type five-point response scale, ranging from strongly disagree (1) to strongly agree (5). The Microsoft form-based questionnaire was emailed to all the students. The average value of six, ten and five items of the three constructs (viz., comparative knowledge gained, comparative level of interaction and comparative ease) were extracted. Three more variables that are categorical; namely, comparative knowledge gained (CKG): dissimilar/inferior and similar/superior, intensities (high and low) of comparative interaction level (CIL_L) and comparative ease (CE_L) were created. Each participant was categorised as dissimilar/ inferior CKG if the mean value of respondents was less than 3.456 of the 'construct;' and vice versa. Further, each participant was categorised as low LCI, if the mean value of that respondent was less than or equal to the overall mean value (2.900) of that construct, and vice versa. Similarly, each respondent was categorised as low CE if the mean value of that participant was less than or equal to overall mean value (2.514) of that construct and vice versa. The descriptive statistics of the 
variables under study is presented in Table 1.

The present study applied descriptive statistics and the binary logistic regression model to pursue the research objectives of the study; the binary logistic regression model has been preferred as a tool for predicting the outcome of dissimilar/inferior or similar/superior about the comparative knowledge gained from two predictors: intensities of comparative ease of attending and comparative level of interaction in online classes. The rationale behind employing binary logistic regression is that it is well suited for describing and testing hypotheses about relationships between a categorical outcome variable and one or more categorical or continuous predictor variables (Peng, Lee, \& Ingersoll, 2002). The study proposes the following model:

$$
\text { Logit }(\mathrm{Y})=\log \text { odds }=\ln \left(\frac{P}{1-p}\right)=\mathrm{a}+\mathrm{b}_{1} \mathrm{X}_{1}+\mathrm{b}_{2} \mathrm{X}_{2}+\ldots \mathrm{e}_{\mathrm{i}}
$$

Where,

Logit $(\mathrm{Y})=$ the log odds of ratio of probability of outcome of similarity/superior (p) to probability of outcome of dissimilarity/inferior (1-p) of the comparative knowledge gained from online classes

ln = natural logarithm

$\mathrm{a}=$ intercept

$\mathrm{b}_{1}=$ regression coefficient of the categorical variable $\mathrm{X}_{1}$

$\mathrm{b}_{2}=$ regression coefficient of the variable $\mathrm{X}_{2}$

$\mathrm{x}_{1}=$ categorical variable comparative ease of attending online class

$\mathrm{x}_{2}=$ categorical variable comparative interaction level in online class

$\mathrm{e}_{\mathrm{i}}=$ the error term

\subsection{Reliability analysis}

To ensure the reliability - the degree to which an instrument produces similar results at different periods (Gray, 2014), the present study calculated the Cronbach's alpha, the coefficient of internal consistency which is used as an estimate of the reliability.

The coefficient of Cronbach's alpha was computed for Comparative Knowledge Gained (6 items), Comparative Interaction Level (10 items) and Comparative Ease (5 items) for which the Cronbach's alpha has figured 0.893, 0.908 and 0.76 respectively, as shown in Appendix 1. Since these coefficients (calculated values) of Cronbach's alpha are greater than 0.70 (Hair, Black, Babin, Anderson, \& Tatham, 2009), the three variables consisting in the questionnaire have been inferred as reliable. Hence, further tests can be administered on so reliable data.

\subsection{Limitations of the study}

The study covers the students pursuing management courses (viz., MBA, MSDMG and BBS) at Nepal Open University (NOU) only. It can, however, be justified on the ground that it is only NOU that exclusively offers online classes in Nepal even before and after the outbreak of coronavirus pandemic; while other university programmes currently follow either a distance learning mode or a blended one; instead of an exclusive online mode. Further, the questionnaire used in the study required the respondents to compare their present experience of online classes (learning) with their previous experience with the face-to-face learning, which they had had during their previous academic degrees (bachelors and 
undergraduate). It is obvious that the respondents have been rendered capable of making comparisons between the two modes of learning, as they were previously engaged in traditional, face-to-face learning mode till the point they have joined their current alma mater Nepal Open University that has exposed them to the online mode of learning in their latest study-life. Since present study was conducted prior to the COVID-19 pandemic, it does not encompass the virtual learning issues specific of the pandemic.

\section{Data analysis}

Table 1 exhibits the descriptive statistics of the variables under study. The present study has used the variables of 'comparative interaction level' and 'comparative ease' to form the categorical variables CIL_L (low and high CIL as intensity types) and CE_L (low and high CE as intensity types); vis-à-vis the comparative knowledge gained (CKG), the major variable of interest. The grand average value (3.456) for CKG (with standard error of 0.060 ) is higher than other variables under study. Thus, the study interprets that the NOU learners perceive the knowledge gained from online mode of learning is similar to that from the face-to-face one.

Descriptive statistics of the variables under study

\begin{tabular}{llccccc}
\hline & \multirow{2}{*}{ Variables } & \multirow{2}{*}{ Mean } & \multirow{2}{*}{ Std. Error } & \multirow{2}{*}{ SD } & \multicolumn{2}{c}{ Skewness } \\
\cline { 6 - 8 } Comparative Knowledge Gained: & CKG & 3.456 & 0.060 & 0.903 & 0.003 & Std. Error \\
Comparative Level of Interaction: & CIL & 2.900 & 0.052 & 0.779 & 0.111 & 0.163 \\
Comparative Ease: & CE & 2.514 & 0.049 & 0.732 & 0.354 & 0.163
\end{tabular}

Note. Calculations based on researchers' survey, 2020

For assessing the impact of varying intensities of comparative interaction level and comparative ease of attending online classes on knowledge gained from online as compared to face-to-face learning, the $\mathrm{T}$ able 2 depicts the binary logistic regression outputs. The coefficient -2.323 indicates that the students perceiving low level of comparative easiness in attending online classes find dissimilar/inferior comparative knowledge gained as compared to face-to-face modes of learning. The finding is further supported by the Wald statistics of 24.371 at one degree of freedom is significant with p value of 0.001 . Similarly, the odd ratio 0.098 indicates that the students finding the similarity/superior about online learning modes is 0.098 times lower for students classified as low intensities of comparative ease.

Table 2

Binary logistic regression analysis

\begin{tabular}{|c|c|c|c|c|c|c|c|c|c|}
\hline Variables & B & S.E. & Wald & $\mathrm{df}$ & Sig. & $\operatorname{Exp}(B)$ & & & \\
\hline CE_L(1) & 2.323 & 0.471 & 24.371 & 1 & 0.001 & 0.098 & $-2 \log$ & $\begin{array}{c}\text { Cox \& } \\
\text { Snell R }\end{array}$ & Nagelkerke \\
\hline CIL_L(1) & 4.053 & 0.645 & 39.535 & 1 & 0.001 & 0.017 & likelıhood & Square & K square \\
\hline Constant & 1.617 & 0.294 & 30.213 & 1 & 0.001 & 5.037 & 131.650a & 0.509 & 0.7 \\
\hline
\end{tabular}

a Estimation terminated at iteration number 6 because parameter estimates changed by less than .001 . Note: Calculations based on researchers' survey, 2020 
Further the coefficient -4.053 supports the hypothesis that the students perceiving low level of interaction in online classes find dissimilar/inferior comparative knowledge gained as compared to the face-to-face mode of learning. The finding is further supported by the Wald statistics of 39.535 at one degree of freedom with significance of 0.001 . Similarly, the odd ratio 0.017 indicates that the students finding the similarity/superior about online learning modes is 0.017 times lower for students classified as low intensities of comparative interaction level in online classes. The pseudo R2 values range from 50.9 per cent (Cox \& Snell R Square) to $70 \%$ (Nagelkerke R Square).

Table 3

Omnibus tests of model coefficients

\begin{tabular}{llll}
\hline Step 1 & Chi-square & df & Sig. \\
\hline Step & 159.142 & 2 & 0.001 \\
Block & 159.142 & 2 & 0.001 \\
Model & 159.142 & 2 & 0.001 \\
\hline
\end{tabular}

Note: Calculations based on researchers'survey, 2020

The Table 3 exhibits the omnibus tests of model coefficients outputs to determine whether the inclusion of covariates under the study have a significant influence on the binary outcome of the variable: comparative knowledge gained. The omnibus tests of model coefficients output table show the results of a chi-square test and has produced a p-value of .018, making the comparative knowledge gained model significant at $5 \%$ level, after inclusion of intensities of comparative ease and comparative interaction level in the logistic regression model.

Table 4

Block 1 classification table

\begin{tabular}{llccc}
\hline \multirow{2}{*}{ Observed } & \multicolumn{3}{c}{ Predicted } \\
\cline { 3 - 4 } & \cline { 2 - 3 } & \multicolumn{3}{c}{$\begin{array}{c}\text { Percentage } \\
\text { Correct }\end{array}$} \\
\cline { 3 - 4 } CKG & Dissimilar/Inferior & Similar/Superior & 91.7 \\
& Inferior & 133 & 12 & 86.1 \\
\hline & Similar/Superior & 11 & 68 & 89.7 \\
\hline
\end{tabular}

a The cut value is .500

Table 4 exhibits the block one classification of predicting the variable comparative knowledge gained into two categories of dissimilar/inferior and similar/superior using two covariates under study. The model correctly predicts 91.7 and 86.1 percentage of times about the dissimilarity and similarity respectively. The cut value is .500. This means that if the probability of a case being classified into the similar/superior category is greater than .500 , then that particular case is classified into the similar/superior category. Otherwise, the case is classified as in the dissimilar/inferior category. The pictorial representation of the observed and predicted probabilities is exhibited in Appendix 3. The correct classification rate has increased by $25 \%(89.7 \%-64.7 \%)$ to $89.7 \%$ (See Appendix 4 ). 
undergraduate). It is obvious that the respondents have been rendered capable of making comparisons between the two modes of learning, as they were previously engaged in traditional, face-to-face learning mode till the point they have joined their current alma mater Nepal Open University that has exposed them to the online mode of learning in their latest study-life. Since present study was conducted prior to the COVID-19 pandemic, it does not encompass the virtual learning issues specific of the pandemic.

\section{Data analysis}

Table 1 exhibits the descriptive statistics of the variables under study. The present study has used the variables of 'comparative interaction level' and 'comparative ease' to form the categorical variables CIL_L (low and high CIL as intensity types) and CE_L (low and high CE as intensity types); vis-à-vis the comparative knowledge gained (CKG), the major variable of interest. The grand average value (3.456) for CKG (with standard error of 0.060) is higher than other variables under study. Thus, the study interprets that the NOU learners perceive the knowledge gained from online mode of learning is similar to that from the face-to-face one.

Table 5

Observed and predicted probability deviation test

\begin{tabular}{|c|c|c|c|c|c|c|c|}
\hline \multirow{4}{*}{\multicolumn{2}{|c|}{$\begin{array}{c}\text { Hosmer and } \\
\text { Lameshow Test }\end{array}$}} & \multicolumn{6}{|c|}{ Contingency Table for Hosmer and Lemeshow Test } \\
\hline & & \multirow{3}{*}{ Step 1} & \multirow{2}{*}{\multicolumn{2}{|c|}{$\begin{array}{l}\mathrm{CKG}= \\
\text { milar/Inferior }\end{array}$}} & \multirow{2}{*}{\multicolumn{2}{|c|}{$\begin{array}{l}\text { CKG }= \\
\text { ilar/Superior }\end{array}$}} & \multirow{3}{*}{ Total } \\
\hline & & & & & & & \\
\hline & & & Observed & Expected & Observed & Expected & \\
\hline \multicolumn{2}{|c|}{ Step 1} & 1 & 86 & 87.252 & 2 & 0.748 & 88 \\
\hline $\begin{array}{c}\text { Chi } \\
\text { Square }\end{array}$ & 3.267 & 2 & 27 & 25.748 & 1 & 2.252 & 28 \\
\hline $\mathrm{df}$ & 2 & 3 & 20 & 18.748 & 8 & 9.252 & 28 \\
\hline Sig & 0.195 & 4 & 12 & 13.252 & 68 & 66.748 & 80 \\
\hline
\end{tabular}

Note: Calculations based on researchers' survey, 2020

Further, for robustness check the study conducted 'Hosmer and Lameshow' test to determine whether the predicted probabilities deviate from the observed probabilities in a way that the binomial distribution does not predict. The insignificant value of 0.195 for the chi square value of 3.267 at two degrees of freedom in Hosmer and Lameshow test provided evidence of having the good fit of the logistic regression model. The contingency table for Hosmer and Lameshow test for four groups show the frequency of observed and expected outcome of the variable comparative knowledge gained under two categories of similarity and dissimilarity to be almost similar. The pictorial representation of the observed and expected frequency of outcome variable at different groups is in Appendix 4.

\section{Discussion and Conclusion}

The present paper examined the effect of intensities of comparative interaction level (CIL_L) and comparative ease of attending online classes (CE_L) on comparative knowledge gained from online and face-to-face learning modes. Further, the present study also aimed at investigating the students' perception of equivalence between online and face-to-face courses on the dimension of comparative knowledge gained across intensities of CIL_L and CE_L. The study employed descriptive statistics and binary logistic regression analysis in the survey which covered all the Bachelors' and Masters' level 
students pursuing their business/ management programmes being offered by the Faculty of Management \& Law at the. The study discovered the intensities of comparative easiness in attending online classes has a significant effect on comparative knowledge gained. The findings are consistent with the results of Platt et al. (2014); Bee and Usip (1998); Burns (2013), Tallent-Runnels et al. (2006) and Sthapit and Shrestha (2020); they all inferred that students' longer experience with and exposure to online classes made a positive impact on comparative knowledge gained.

Similarly, the present study also discovered that the intensities of the comparative interaction level had the significant effect on comparative knowledge gained. The result is in line with the findings of Bourzgui et al. (2020); and Sthapit and Shrestha (2020) that all emphasised on the higher level of interaction in the eLearning system (on both online and blended modes) would result to the higher level of comparative knowledge gained. The result should prove to be obvious as the NOU's online learning mode exclusively features synchronous or real-time classes (on Microsoft Teams, previously Skype for Business) that provide its learners plenty of opportunities to interact with the teacher and fellow learners. NOU also integrates its synchronous mode with an asynchronous one where pre-recorded ready-to-use learning materials are also uploaded on the Moodle-based Learning Management System or LMS (NOU, 2020).

In this background, the study concludes that comparative knowledge gained by the students is significantly affected by the intensities of interactions with their course instructors. Subsequently, collaborations in online classes - if made effective - can help students enhance their knowledge acquisition in the subject matter; the result has, thus come in accordance with the social learning hypotheses, which advocates that viability of courses rely upon association among students and instructors. Since learning happens in the social setting, online classes additionally make a quality of a mini society; therefore, students can acquire information through the expanded degrees of cooperation with the instructors and other students during the online classes. Likewise, how much information students gain from the two methods of learning is additionally altogether impacted by the intensities of easiness of going to the innovation empowered' virtual classes opposite traditional face-to-face classes. Elevating students' access required advancements and eliminating potential specialised glitches could make it simpler for them to acquire information also from virtual classes.

Funding: The authors declare receiving no funding or financial support in carrying out the research.

Conflict of interest: Authors declare that they have no potential conflict of interest in the research work.

\section{References}

Allen, E., \& Seaman, J. (2011). Going the distance: Online education in the United States. Babson Survey Research Group. Retrieved from http://www.onlinelearningsurvey. com/reports/ goingthedistance.pdf

Anderson, T. (2003). Getting the mix right: An updated and theoretical rationale for interaction. International Review of Research in Open and Distance Learning, 4(2). doi:10.19173/ irrodl.v4i2.149 
Anderson, T. (Ed.). (2008). The theory and practice of online learning. Edmonton, AB: AU Press. Retrieved March 12, 2020, from http://biblioteca.ucv.cl/site/colecciones/ manuales_u/99Z_Anderson_2008Theory_and_Practice_of_Online_Learning.pdf\%20

Archer, W., Garrison, R., \& Anderson, T. (1999). Adopting disruptive technologies in traditional universities: Continuing education as an incubator for innovation. Canadian Journal of University Continuing Education, 25(1), 3-30.

Bandura, A. (1977). Social Learning Theory. Englewood Cliffs, NJ: Prentice Hall.

Bartley, S. J., \& Golek, J. H. (2001). Evaluating the cost effectiveness of online and face-to-face instruction. Educational Technology \& Society, 7(4), 167-175.

Bee, R. H., \& Usip, E. E. (1998). Differing attitudes of economics students about Web-based instruction. College Student Journal, 32(2), 258-269.

Berge, Z. L. (1999). Interaction in post-secondary web-based learning. Educational Technology, 39(1), 5-11.

Bourzgui, F., Alami, S., \& Diouny, S. (2020). A comparative study of online and face-to- face learning in dental education. EC Dental Science, 19(3), 1-11. Retrieved from htpps://www. researchgate.net/publication/339948717

Bhat, S. (2020, March 12). elearning Industry. Retrieved from https://elearningindustry.com/ reasons-why-online-learning-face-to-face-learning

Burns, B. (2013). Students' perceptions of online courses in a graduate adolescence education program. MERLOT Journal of Online Learning and Teaching, 9(1), 13-25. Retrieved March 17, 2020, from http://jolt.merlot.org/vol9no1/burns_0313.htm

Carliner, S. (1999). Overview of Online Learning. Amherst, MA: Human Resource Development Press.

Clark, R. A., \& Jones, D. (2001). A comparison of traditional and online formats in a public speaking course. Communication Education, 50, 109-124. doi:10.1080/03634520109379238

Cryan, J. R., Mentzer, G., \& Teclehaimanot, B. (2007). Two peas in a pod? A comparison of face-to-face and web-based classrooms. Journal of Technology and Teacher Education, 15, 233-246. Retrieved from https://www.learntechlib.org/primary/p/19863/

Dahlberg, L. (2004). Internet research tracings: Towards non-reductionist methodology. Journal of Computer Mediated Communication, 7(1). doi:10.1111/j.1083-6101.2004.tb00289.x Dewey, J. (1938). Experience and education. New York: Macmillan.

Dron, J. (2007). Control and Constraint in e-learning: Choosing When to Choose. Hershey, PA: Information Science Hub.

Farinella, J. A., Hobbs, B. K., \& Weeks, H. S. (2000). Distance delivery: The faculty perspective. Financial Practice and Education, 10, 184-194. 
Garrison, D. R., Anderson, T., \& Archer, W. (2001). Critical thinking, cognitive presence and computer conferencing in distance education. American Journal of Distance Education, 15(1), 7-23.

Gautam, D.K., \& Gautam, P.K. (2021). Transition to online higher education during COVID-19 pandemic: turmoil and way forward to developing country of South Asia-Nepal, Journal of Research in Innovative Teaching \& Learning, 14 (1), 93-111. DOI: 10.1108/JRIT-102020-0051

Gray, D.E. (2014). Doing research in the real world ( $3^{\text {rd }}$ ed). London: Sage Publications. Green, S. B. (1991). How many samples does it take to do a regression analysis? Multivariate Behavioral Research, 26(3), 499-510.

Hair, J.F., Black, W.C., Babin, B.J., Anderson, R.F. \& Tatham, R.L. (2009). Multivariate data analysis ( $6^{\text {th }}$ ed.), Delhi, India: Pearson Education/ Prentice Hall.

Hollerbach, K., \& Mims, B. (2007). Choosing wisely: A comparison of online, televised, and face-to-face instructional methods on knowledge acquisition of broadcast audience concepts. Journalism and Mass Communication Educator, 62, 176-189. doi:10.1177/107769580706200205

Horspool, A., \& Yang, S. S. (2010). A comparison of university student perceptions and success learning music online and face-to-face. MERLOT Journal of Online Learning and Teaching, 6, 15-29. Retrieved March 29, 2020, from http://jolt.merlot.org/vol6no1/ horspool_0310.pdf

Johnson, S. D., Aragon, S. R., Shaik, N., \& Palma-Rivas, N. (2000). Comparative analysis of learner satisfaction and learning outcomes in online and face-to-face learning environments. Journal of Interactive Learning Research, 11, 29-49. Retrieved April 6, 2020, from http://editlib.org/p/8371/

Kearsley, G. (2000). Online Education: Learning and Teaching in Cyberspace. Stamford, CT: Wadsworth.

Khan, B. (1997). Web Based Instruction: What is it and Why is it? In B. H. Khan, Web Based Instruction (pp. 5-18). Englewood Cliffs, NJ: Educational Technology Publications.

Koory, M. A. (2003). Differences in learning outcomes for the online and F2F versions of "An introduction to Shakespeare. Journal of Asynchronous Learning Networks, 7, 18-35.

Laurillard, D. (1997). Rethinking university teaching: A framework for the effective use of educational technology. London: Routledge.

Lederman, D. (2019, October). Professors' slow, steady acceptance of online learning: A survey, Insidehighered. Retrieved May 12, 2020, from https://www.insidehighered.com/ news/survey/professors-slow-steady-acceptance-online-learning-survey?mc_cid= 2945ba851e\&mc_eid =e50f233812 
Nguyen, T. (2015). The effectiveness of online learning: Beyond no significant difference and future horizons. MERLOT Journal of Online Learning and Teaching, 11(2), 309-319.

NOU. (2020). About Nepal Open University. Retrieved May 12, 2020, from Nepal Open University Official Website: https://nou.edu.np/about-nou

ODEC. (2020). About ODEC Tribhuvan University. Retrieved May 12, 2020, from ODEC Official Website: http://www.odectu.edu.np/index.php

Pape, L. (2010). Blended teaching and learning. School Administrator, 67(4), 16-21.

Platt, C. A., Ralie, A. N., \& Yu, N. (2014). Virtually the same? Student perceptions of the equivalence of online classes to face to face classes. MERLOT Journal of Online Learning and Teaching, 10(3), 489-503. Retrieved from https://jolt.merlot.org/ vol10no3/Platt_0914.pdf

Peng, C.Y. J., Lee, K. 1., \& Ingersoll, G. M. (2002). An introduction to logistic regression analysis and reporting. The Journal of Educational Research, 96(1), 3-14. Retrieved from http://bit. csc.lsu.edu/ jianhua/emrah.pdf

Ritchie, D. C., \& Hoffman, B. (1997). Incorporating Instructional Design Principles with the World Wide Web. Englewood Cliffs, NJ: Educational Technology Publications.

Schettini, C., Amendola, D., Borsini, I., \& Galassia, R. (2020). A blended learning approach for general chemistry modules using a Moodle platform for first year academic students. Journal of E-Learning and Knowledge Society, 16(2), 61-72. doi: htt ps://10.20368/1971-8829/1135197

Shank, G. (1993). The semiotic dynamics of navigating the net. The Arachnet Electronic Journal on Virtual Culture, 1(1).

Sthapit, A. (2020). International business: Environments and strategies ( $2^{\text {nd }}$ ed.). Kathmandu: Taleju Prakashan.

Sthapit, A., \& Shrestha, B. (2020). Comparative knowledge gained from online and face-to-face learning modes in management courses in Nepal. Journal of Business and Social Sciences Research, 5(1), 35-50. doi:10.3126/jbssr.v5i1.30197

Tallent-Runnels, M. K., Thomas, J. A., Lan, W. Y., Cooper, S., Ahern, T. C., \& Shaw, S. M. (2006). Teaching courses online: A review of the research. Review of Educational Research, 76, 93135. doi:10.3102/00346543076001093

Valdez, G., McNabb, M., Foertsch, M., Anderson, M., Hawkes, M., \& Raack, L. (2000). Computer based technology and learning: Evolving uses and expectations. North Central Regional Educational Laboratory. Retrieved from http://www.ncrel. org/ tplan/cbtl/toc.htm

Visser, J. (2000). Faculty work in developing and teaching web-based distance courses: A case study of time and effort. American Journal of Distance Education, 14(3), 21-32.

Zinn, L. M. (1990). Identifying Your Philosophical Orientation. In M. Galbraith, Adult Learning Methods (pp. 39-77). Malabar, FL: Krieger. 


\section{Appendices}

Appendix 1

Reliability analysis (Cronbach's alpha coefficients)

\begin{tabular}{lcc}
\hline Variables & Cronbach's Alpha & No. of retained items \\
\hline CKG (Comparative Knowledge Gained) & 0.893 & 6 \\
CIL (Comparative Interaction Level) & 0.908 & 10 \\
CE (Comparative Ease) & 0.760 & 5 \\
\hline
\end{tabular}

Note: Calculations based on researchers' survey, 2020

\section{Appendix 2}

Respondent profile

\begin{tabular}{lccc}
\hline Gender & Frequency & Per cent & Cumulative Per cent \\
\hline Male & 204 & 91.1 & 91.1 \\
Female & 20 & 8.9 & 100 \\
Total & 224 & 100 & \\
\hline \multicolumn{4}{l}{ Panel B: Currently pursuing online education level of the respondents } \\
\hline Pursuing_Online_Education & Frequency & Per cent & Cumulative Per cent \\
\hline Masters & 140 & 62.5 & 62.5 \\
Bachelors & 84 & 37.5 & 100 \\
Total & 224 & 100 & \\
\hline Panel C: Education background & & & \\
\hline Education Background & Frequency & Per cent & Cumulative Per cent \\
\hline Management \& Others & 172 & 76.8 & 76.8 \\
Science \& Technology & 52 & 23.2 & 100 \\
Total & 224 & 100 & \\
\hline Panel D: Age group of the respondents & & & \\
\hline Group_Age & Frequency & Per cent & Cumulative Per cent \\
\hline More than 30 & 136 & 60.7 & 60.7 \\
30 \& less than 30 & 88 & 39.3 & 100 \\
Total & 224 & 100 & \\
\hline
\end{tabular}

Note: Calculations based on researchers' survey, 2020 


\section{Appendix 3}

Observed groups and predicted probabilities
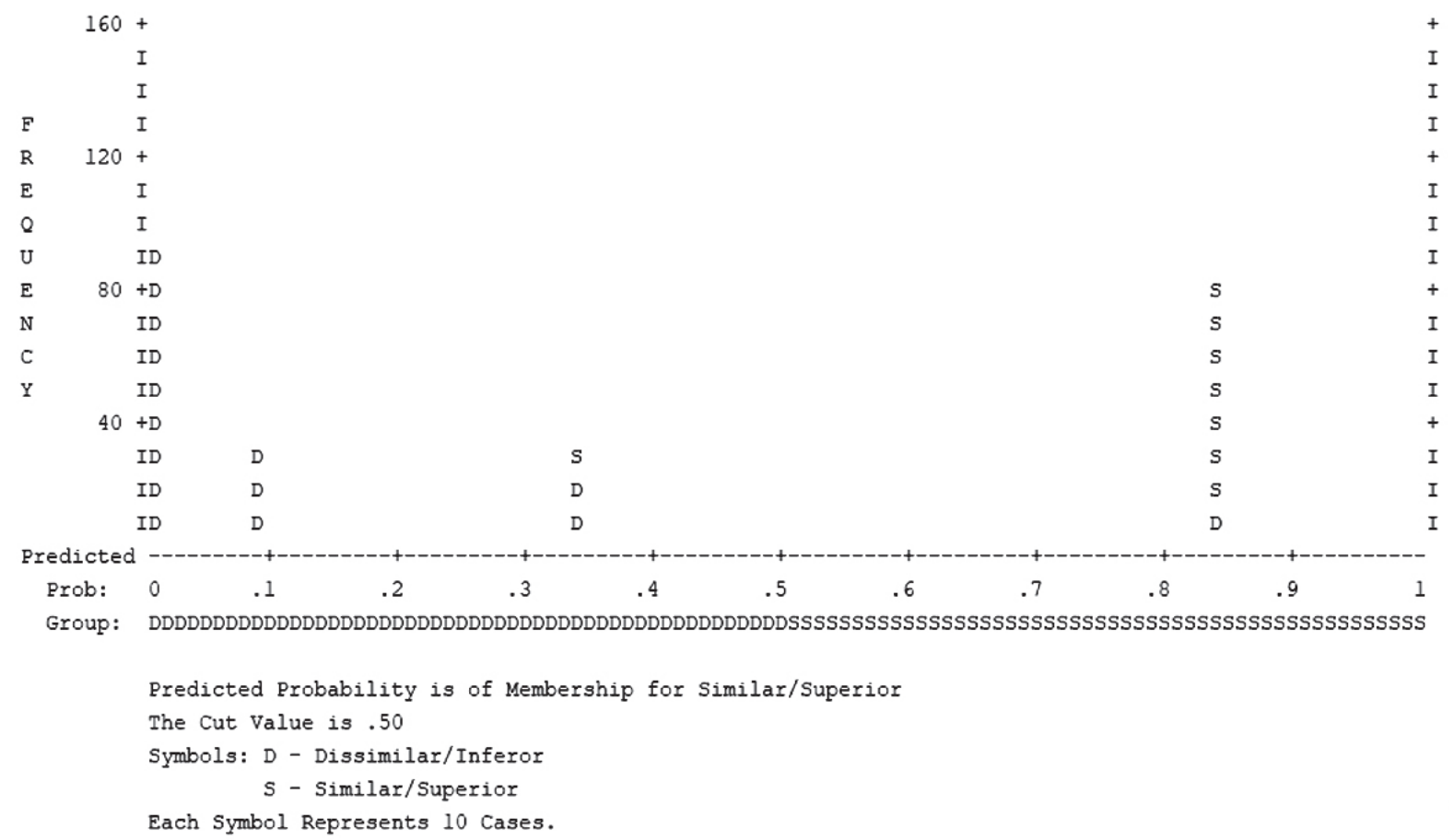

\section{Appendix 4}

Block 0 classification table ${ }^{b}$

\begin{tabular}{ccccc}
\hline & & \multicolumn{2}{c}{ Predicted } & Percentage \\
\cline { 3 - 4 } Observed & Dissimilar/ & CKG & Correct \\
\cline { 3 - 4 } CKG & Inferior & 145 & 0 & 100 \\
& Similar/Superior & 79 & 0 & 0 \\
\hline Overall Percentage & & & 64.7 \\
\hline
\end{tabular}

b The cut value is .500 